\title{
Otimização do processo de transporte intra-hospitalar de pacientes a partir de acionamento remoto de auxiliares (e-hailing)
}

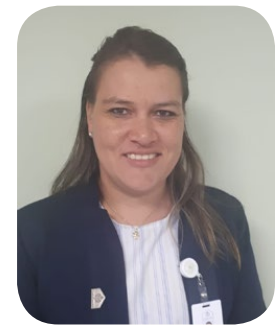

\author{
Milena Souza Silva, Allyson Gabriel Bortoli, Edilvane Xavier \\ Barretto, Hérica Jacy Lima de S. Serrão, Paulina dos Reis Novaes \\ e Luciano de Souza Lima
}

\section{INTRODUÇÃO}

Dentro da estrutura de serviços de apoio no Hospital Santa Izabel, o serviço de transporte intra-hospitalar de paciente representa uma etapa fundamental para os devidos fluxos assistenciais, interligando etapas imprescindíveis para toda a cadeia das linhas de cuidados.

A falta de compartilhamento eficiente dos recursos, em um processo descentralizado, retroalimentava a ineficiência do serviço e consequentemente agravava o seu baixo nível de satisfação, o que motivou o desenvolvimento do projeto de melhoria do serviço de transporte intra-hospitalar, utilizando a metodologia LeanSix Sigma.

O projeto atuou na otimização do processo de transporte de paciente, de modo a permitir uma melhor distribuição das equipes, possibilitando suprir toda a demanda, inicialmente não atendida, reduzir a variação do tempo de atendimento de transporte de pacientes e melhorar a satisfação do cliente interno.

\section{METODOLOGIA}

O projeto se baseou desde o princípio na escuta do cliente, identificando suas necessidades e dificuldades com o processo de transporte de paciente. O projeto seguiu a metodologia DMAIC para definir, medir, analisar, implementar ações e controlar o desempenho para otimizar o processo de transporte intra-hospitalar de paciente. "Não se gerencia o que não se mede" (DEMING, 1950).

Por não haver uma base histórica foi utilizada medição manual dos tempos, coletados no mês de abril. Os dados referentes às escalas de colaboradores foram extraídos através de relatórios fornecidos pela Coordenação de Pessoal. Os relacionados à demanda não atendida foram coletados em sistema através do BI Business Intelligence, em que constam os registros dos pacientes deslocados para realização de procedimentos, exames, admissões, altas, óbitos e transferências.

A medição dos tempos dos transportes foi registrada em etapas:

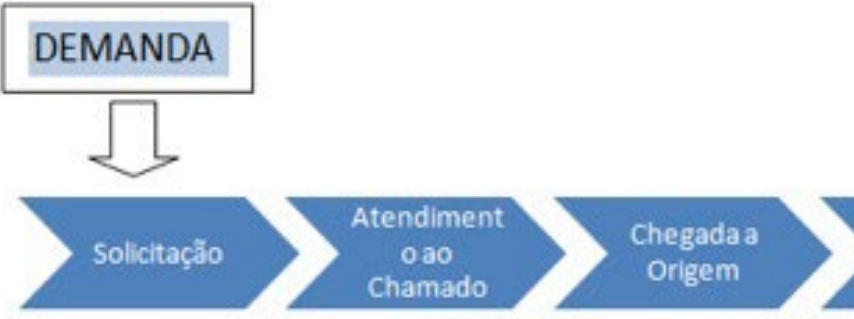

Figura 1 - Etapas do processo de transporte de paciente 


\section{Análise de Demanda x Capacidade}

Para análise de demanda e capacidade, consolidou-se os dados coletados de acordo com as equipes de transporte, dias da semana e intervalos de horas (ao longo de 24 horas do dia).

A partir da alocação de colaboradores conforme as escalas de trabalho e considerando um aprovei- tamento efetivo de $82 \%$ da carga horária, estabeleceu-se a capacidade disponível. Já a demanda foi consolidada a partir dos registros em sistema e mediana dos tempos de transporte, medidos.

Comparando a disponibilidade de auxiliares (capacidade) e a projeção da necessidade (demanda), identificou-se, ao longo dos dias, os níveis de ociosidade e gargalos por intervalo de hora.

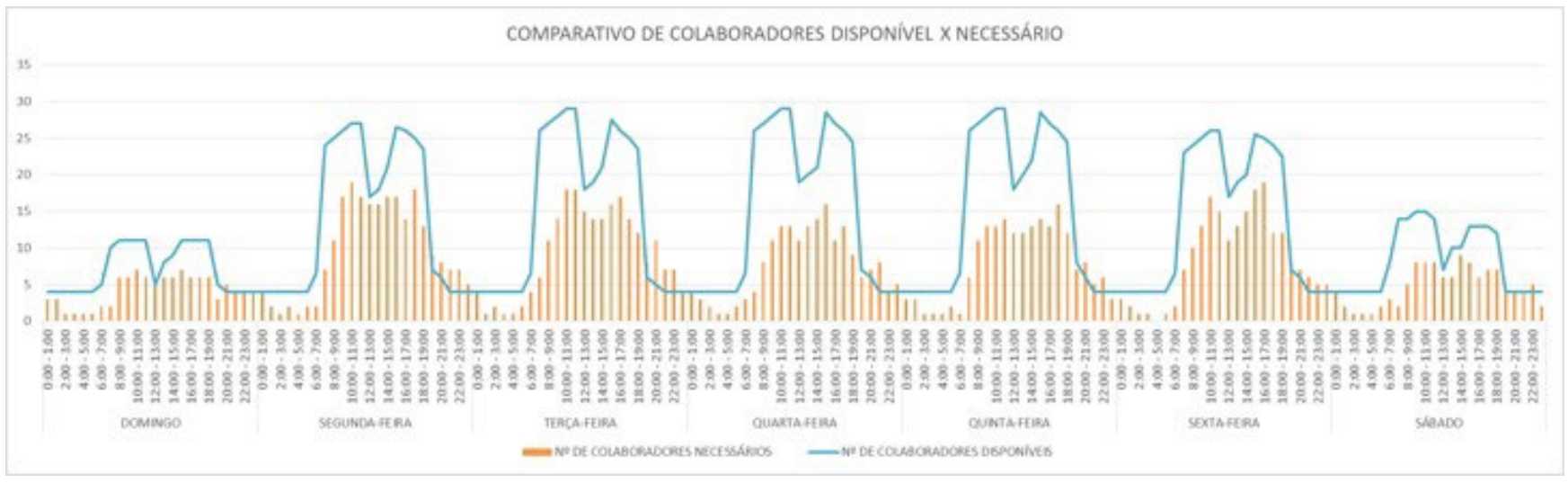

Gráfico 1 - Comparativo de colaboradores disponível x necessário

$\mathrm{Na}$ representação gráfica acima percebe-se a capacidade ociosa da equipe de auxiliares quando comparada à necessidade de acordo com a demanda por horário. Em alguns horários pontuais há demanda superior à capacidade de atendimento.

DEMONSTRATIVO DO NN DE COLABORADORES COM AMPUAÇÄO DA DEMANDA

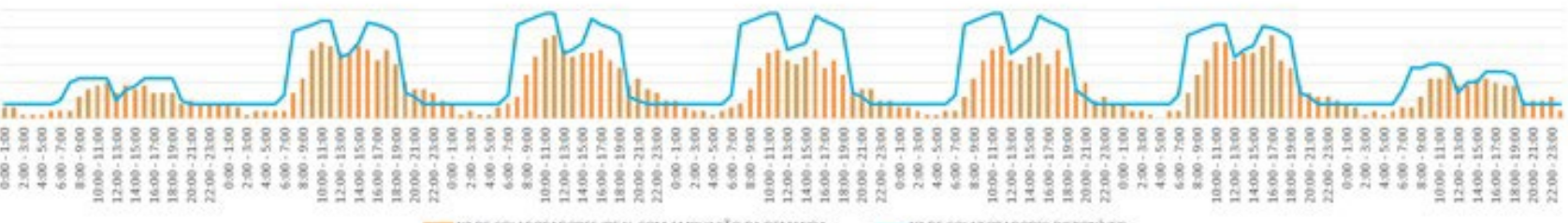

Gráfico 2 - Demonstrativo do $n^{\circ}$ de colaboradores com ampliação da demanda

Considerando a ociosidade identificada no processo atual, foi projetado no gráfico acima a viabilidade de se absorver a demanda atualmente não atendida (19\%) com o mesmo quantitativo de colaboradores.

A partir da demanda total, somada a demanda não atendida, foi calculado o número de colaboradores necessários por hora, simulado a partir das escalas disponíveis. Chegou-se ao número mínimo de colaboradores necessários para atender a demanda por transporte, o que representa apenas 45 colaboradores, somados a 6 colaboradores para cobertura de férias e afastamentos. Isso representa uma potencial redução de 3 colaboradores, mesmo com a ampliação da demanda atendida.

\section{A MELHORIA}

Solução Mobile (e-hailing):

Tecnologia para um salto qualitativo de gestão

A aplicação da metodologia LeanSix Sigma no serviço de transporte intra-hospitalar de paciente permitiu 
ao Hospital Santa Izabel identificar oportunidades para ampliação do atendimento da demanda de transporte devido à evidência de ociosidade das equipes descentralizadas de transporte.

Dentre as melhorias implementadas, destaca-se a idealização e implantação de sistema de Gestão Operacional do Serviço de Transporte, o TEP, que viabiliza todos os registros de etapas e profissionais envolvidos ao longo do processo, com registros através de QRcode ou código de barras.

A solução integrada do aplicativo mobile para viabilizar o controle de todo o processo, desde a solicitação do transporte, onde o solicitante registra via sistema o paciente, unidade (origem/destino), tipo de transporte (interno/externo), possível uso de dispositivo (oxigênio, sonda) e equipamento (cadeira/maca).

O acionamento é realizado diretamente aos dispositivos móveis dos auxiliares de transporte, via post notification, de forma estratificada por geolocalização (agrupamento) e status de disponibilidade. A partir do aceite pelo profissional de transporte, todas as etapas são registradas ao longo do processo, proporcionando segurança, informações detalhadas de tempos e produtividade da equipe.

Os registros são realizados a partir de leitura ótica com QRcode disponível em cada unidade de atendimento, código de barras na pulseira do paciente e crachá de colaboradores.

O modelo de centralização com gestão única, utilizando ferramentas de controle de todas as etapas do serviço (aplicativo utilizando o e-hailing) viabilizou o gerenciamento dos tempos de atendimento e dos acordos firmados entre os serviços.

\section{Etapas do Processo de Transporte:}

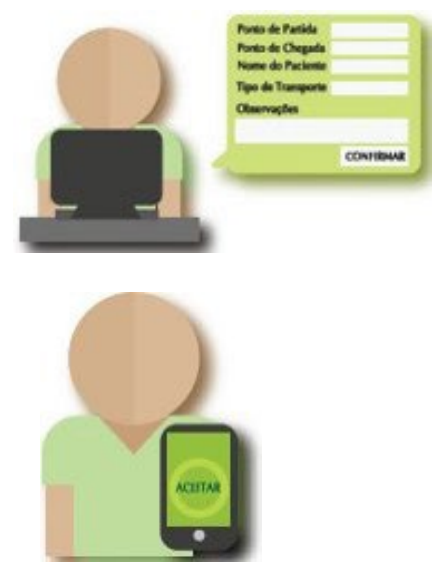
pela área assistencial.

Acionamento chega diretamente nos dispositivos móveis.

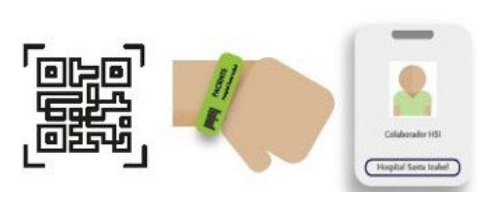

Registros realizados a partir de leitura ótica com QR code disponível em cada unidade.

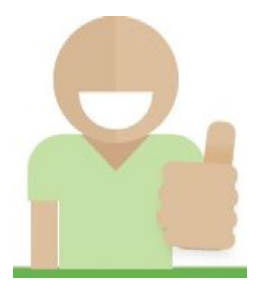

Encerramento já coloca o auxiliar, automaticamente, disponível para o próximo acionamento remoto.

A tecnologia de acionamento remoto com o uso de smartphones, mesma tecnologia utilizada em soluções de acionamento da UBER, permite o fluxo de informações de forma mais rápida, em um processo no qual a equipe está sempre em deslocamento. Paralelamente, o registro de todas as etapas do processo, a partir do registro digitalizado (QR code ou código de barras), possibilita amplo monitoramento do serviço, análise detalhada das etapas e pontos de atenção.

A implantação do aplicativo possibilitou reduzir e controlar o tempo médio de atendimento, o que permitirá até janeiro de 2019 incorporar toda demanda anteriormente não contemplada no escopo de atendimento da Central de Transportes.

Também houve ganho de produtividade da equipe a partir de um melhor dimensionamento das escalas de trabalho dos profissionais e melhor gestão do serviço de transporte.

\section{REFERÊNCIAS}

1. PINTO, Carlos Frederico. Em Busca do Cuidado Perfeito. 2014, Ed. Lean Institute Brasil.

${ }^{1}$ E-hailing é o ato de se requisitar um táxi através de um dispositivo eletrônico, geralmente um celular ou smartphone (www.wikipedia.org)
Allyson Gabriel Bortoli: Gerente de Engenharia Clínica Edilvane Xavier Barretto: Assistente de Diretoria Hérica Jacy Lima de S. Serrão: Gerente de atendimento Luciano de Souza Lima: Gerente de Estudos e projetos Milena Souza Silva: Gerente de Hotelaria

Paulina dos Reis Novaes: Supervisora da Central de Atendimento Farmacêutico

Endereço para correspondência:

milena.silva@santacasaba.org.br 